http://jmscr.igmpublication.org/home/ ISSN (e)-2347-176x ISSN (p) 2455-0450 crossref DOI: https://dx.doi.org/10.18535/jmscr/v9i12.02

\title{
Cytohistological Correlative Study of Thyroid Lesions by Imprint Method
}

\author{
Authors \\ Anjali PV ${ }^{1 *}$, Nataraju $\mathbf{G}^{2}$ \\ ${ }^{1,2}$ Mysore Medical College, Mysore \\ *Corresponding Author \\ Anjali P V
}

\begin{abstract}
Background: Thyroid disorders are common clinical problem which are unique in both clinical presentation and symptoms. Imprint cytology is a simple, inexpensive and rapid diagnostic procedure that can be used in the perioperative diagnosis of thyroid lesions. The current study is designed to study the age, sex profile and the spectrum of various thyroid lesions and to assess the efficacy of imprint cytology by comparing it with histopathology smears.

Method: In our study, conducted over a period of 18 months, imprint cytology of thyroid lesions was done perioperatively. The histopathological diagnosis was considered as the gold standard and imprint cytological diagnosis was compared with it.

Results: In the present study, age of the patient ranged from 14-70 years, with a mean age being 39.24 years. Majority of patients were females with male to female ratio of 1:7.8. Out of the 53 cases studied, 46 cases were diagnosed as benign and7cases were diagnosed as malignant on imprint cytology. On histopathological examination, 45cases were diagnosed as benign and 8 cases were diagnosed as malignant. On cytohistopathological correlation, sensitivity and specificity was found to be $87.5 \%$ and $100 \%$ respectively. The positive predictive value, negative predictive value and diagnostic accuracy was found to be $100 \%, 97.8 \%$ and $98.1 \%$ respectively.

Conclusion: Imprint cytology is a simple, cost effective and rapid intraoperative diagnostic technique which can be a useful guide in making intraoperative therapeutic decision quickly.

Keywords: Thyroid, Imprint cytology, Histopathology, Colloid goitre, Papillary Thyroid Carcinoma, accuracy
\end{abstract}

\section{Introduction}

Thyroid disorders are a common clinical problem which are unique in both clinical presentation and symptoms. The diagnosis of thyroid lesions forms an important aspect involving both the pathologist and the operating surgeon. Since the pathology of the lesion influences the decision to operate and to decide the extent of surgery to be performed, an intraoperative diagnosis becomes necessary. ${ }^{[1]}$

Imprint cytology is a simple, inexpensive and rapid diagnostic procedure that can be used in the perioperative diagnosis of thyroid lesions. It helps in determining the extent of thyroid surgery and thus eliminates the need for second surgery. It can also provide information regarding the histopathological pattern of the lesion. ${ }^{[2]}$

Imprint cytology can be used in minute specimens and those sample which are difficult to cut with cryostat. It is also useful in places where there is lack of trained technicians and equipments needed for frozen section. ${ }^{[3]}$ 
The current study is designed to demonstrate the efficacy of imprint cytology in diagnosis of thyroid lesions and to correlate the findings with histopathology smears.

\section{Aims and Objectives}

1) To study the age, sex profile and the spectrum of various thyroid lesions.

2) To assess the efficacy of imprint cytology by comparing it with histopathological diagnosis.

\section{Methodology}

The present study was conducted in Department of Pathology, Mysore Medical College and Research Institute, Mysore during the study period of 18 months (December 2017 to May 2019). The study included all patients with clinically diagnosed thyroid lesions who underwent thyroidectomy. Imprint smears were taken perioperatively under the guidance of the operating surgeon. The results were correlated with the histopathological diagnosis.

Freshly resected specimen was grossly examined and a fresh cut through the tumor was given. The suspected area was sliced into several thin slices. For small mass, it was bisected. Excess blood or serum was blotted out using a filter paper. The freshly cut surface of tissue is then imprinted onto a clean, grease free glass slide. The slides were immediately fixed in 95\% ethyl alcohol, and stained with routine haematoxylin \& eosin and with PAP stain. The resected specimen was then fixed in $10 \%$ formalin for paraffin sectioning and histopathological examination. The histopathological diagnosis was considered as the gold standard and imprint cytological diagnosis was compared with it.

\section{Inclusion Criteria}

All thyroidectomy specimens received in the Department of Pathology, Mysore Medical College and Research Institute.

\section{Exclusion Criteria: None}

\section{Sample Size Estimation}

Sample size was calculated using $10 \%$ absolute error and 5\% significance and it was found to be 53 .

\section{Statistical Analysis}

Data was entered in Microsoft Excel spreadsheet. Descriptive statistics like frequency and proportions were calculated. Categorical variables were analysed using Pearson Chi-square test.

\section{Results}

In the present study, age of the patient ranged from 14-70 years, with a mean age being 39.24 years (Figure 1). Majority of patients were females (88.68\%) with male to female ratio of 1:7.8.

Out of the 53 cases studied, $46(86.79 \%)$ cases were diagnosed as benign and $7(13.21 \%)$ cases were diagnosed as malignant on imprint cytology. (Table 1)These included colloid goiter (Figure 2), colloid goiter with cystic change, lymphocytic thyroiditis, hyperplastic nodule, follicular neoplasm (Figure 3) and papillary thyroid carcinoma (Figure 4,5).

\section{DISTRIBUTION OF THYROID LESIONS IN DIFFERENT AGE GROUPS}

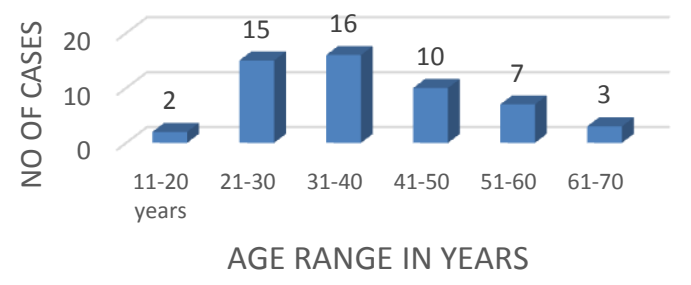

Figure 1: Distribution of thyroid lesions in different age groups

Table1: Distribution of cases based on imprint cytology

\begin{tabular}{|l|c|c|}
\hline Imprint Diagnosis & $\begin{array}{c}\text { No of } \\
\text { Cases }\end{array}$ & Percentage \\
\hline Colloid Goitre with cystic & 31 & $58.49 \%$ \\
\hline $\begin{array}{l}\text { Colloid Goitre wange } \\
\text { change }\end{array}$ & 3 & $5.66 \%$ \\
\hline Lymphocytic thyroiditis & 4 & $7.55 \%$ \\
\hline Hyperplastic Nodule & 3 & $5.66 \%$ \\
\hline Follicular Neoplasm & 5 & $9.43 \%$ \\
\hline Papillary thyroid carcinoma & 7 & $13.21 \%$ \\
\hline Total & 53 & $100 \%$ \\
\hline
\end{tabular}

On histopathological examination, 45(84.90\%) cases were diagnosed as benign and $8(15.10 \%)$ cases were diagnosed as malignant. (Table 2)

Out of 31 cases of colloid goiter which was diagnosed by imprint cytology, 26 cases were 


\section{JMSCR Vol||09||Issue||12||Page 05-10||December}

confirmed to be colloid goiter in histopathology.3 cases were diagnosed as colloid goiter with cystic change, 1 case as Hyperplastic nodule and 1 case as Follicular adenoma in histopathology.

All the cases of colloid goiter with cystic change (3 cases), Hyperplastic nodule (3 cases), and Papillary Thyroid Carcinoma ( 7 cases) were accurately diagnosed in imprint cytology.

Out of 4 cases of lymphocytic thyroiditis, 2 cases were confirmed to be lymphocytic thyroiditis whereas 2 cases were diagnosed as Hashimoto thyroiditis in histopathology.

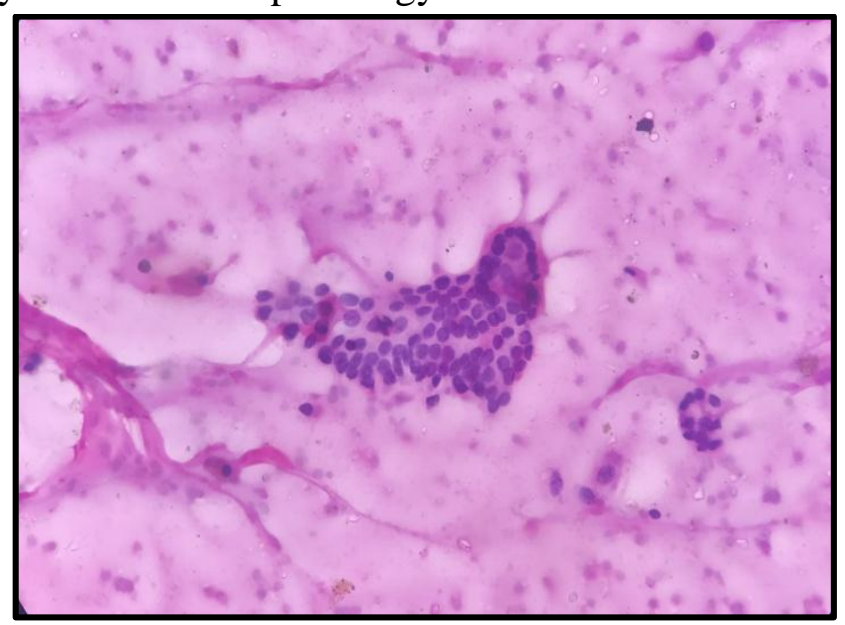

Figure 2: Imprint smear of colloid goiter showing benign thyroid follicular cells arranged in a cluster against background of thick and thin colloid, H\&E,40X.

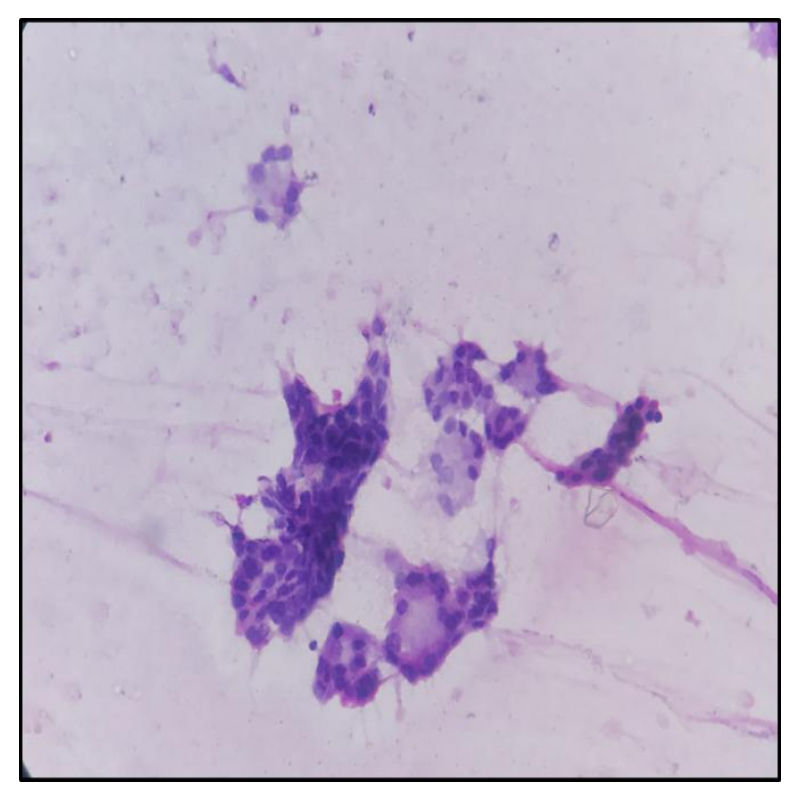

Figure 3: Imprint smear of Follicular neoplasm showing follicular cells arranged in microfollicular pattern, H \& E, 40X
Table 2: Distribution of thyroid lesions based on histopathological diagnosis

\begin{tabular}{|l|c|c|}
\hline Histopathological Diagnosis & $\begin{array}{c}\text { No of } \\
\text { Cases }\end{array}$ & Percentage \\
\hline Colloid Goitre & 26 & $49.06 \%$ \\
\hline $\begin{array}{c}\text { Colloid Goitre with cystic } \\
\text { change }\end{array}$ & 6 & $11.32 \%$ \\
\hline Hyperplastic Nodule & 4 & $7.55 \%$ \\
\hline Lymphocytic thyroiditis & 2 & $3.77 \%$ \\
\hline Hashimoto thyroiditis & 2 & $3.77 \%$ \\
\hline Follicular Adenoma & 5 & $9.43 \%$ \\
\hline Follicular Carcinoma & 1 & $1.89 \%$ \\
\hline Papillary thyroid Carcinoma & 7 & $13.21 \%$ \\
\hline Total & 53 & $100 \%$ \\
\hline
\end{tabular}

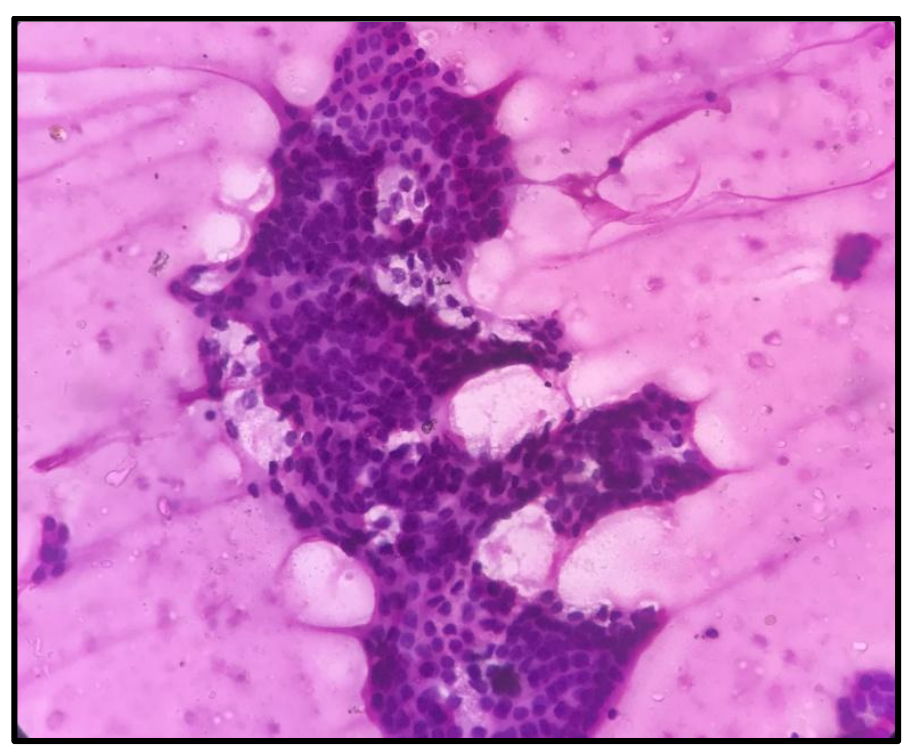

Figure 4: Imprint smear of Papillary thyroid carcinoma showing follicular cells arranged in papillary structure displaying characteristic nuclear features, $\mathrm{H} \& \mathrm{E}, 40 \mathrm{X}$

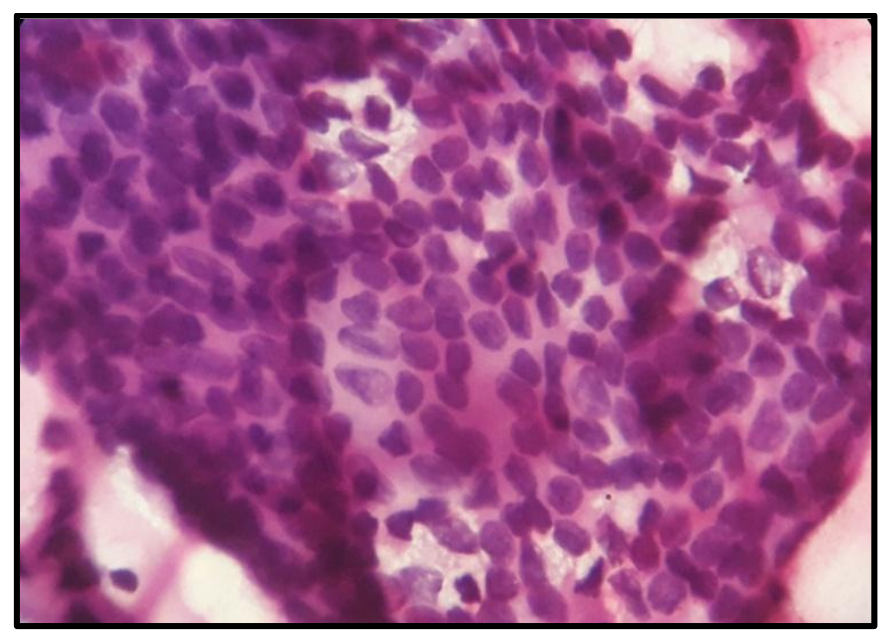

Figure 5: Imprint smear of Papillary thyroid carcinoma showing follicular cells displaying characteristic nuclear features, $\mathrm{H} \& \mathrm{E}, 100 \mathrm{X}$ 


\section{JMSCR Vol||09||Issue||12||Page 05-10||December}

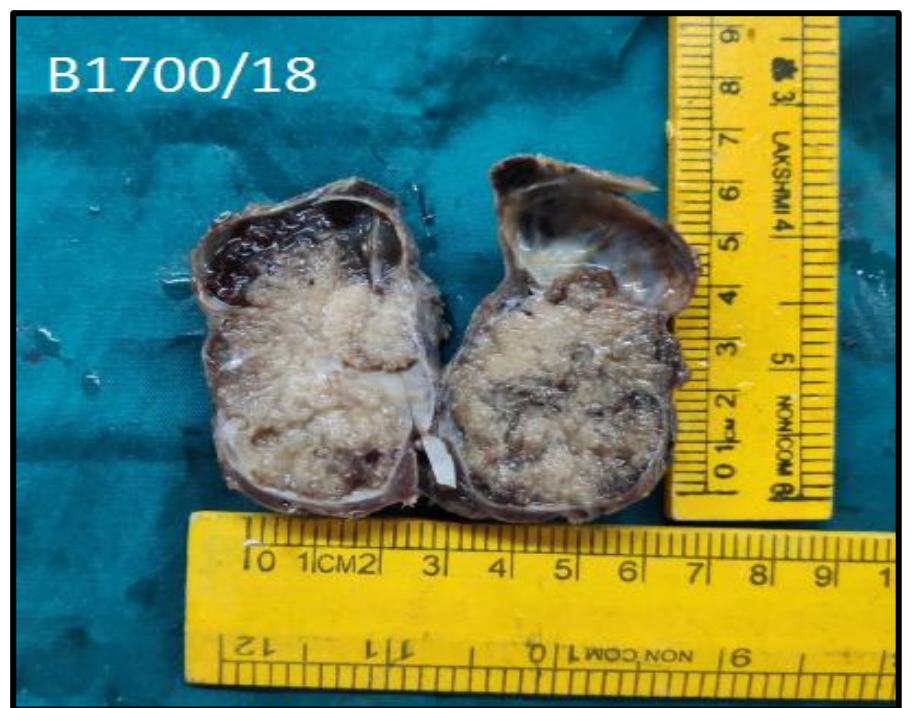

Figure 6: Gross specimen of Papillary thyroid carcinoma showing solid white cut surface

Out of 5 cases of Follicular Neoplasm, 4 cases were diagnosed as Follicular Adenoma. 1 case turned out to be Follicular Carcinoma in histopathology.

The sensitivity and specificity in the present study was found to be $87.5 \%$ and $100 \%$ respectively. The positive predictive value, negative predictive value and diagnostic accuracy was found to be $100 \%, 97.8 \%$ and $98.1 \%$ respectively. (Table 3 )

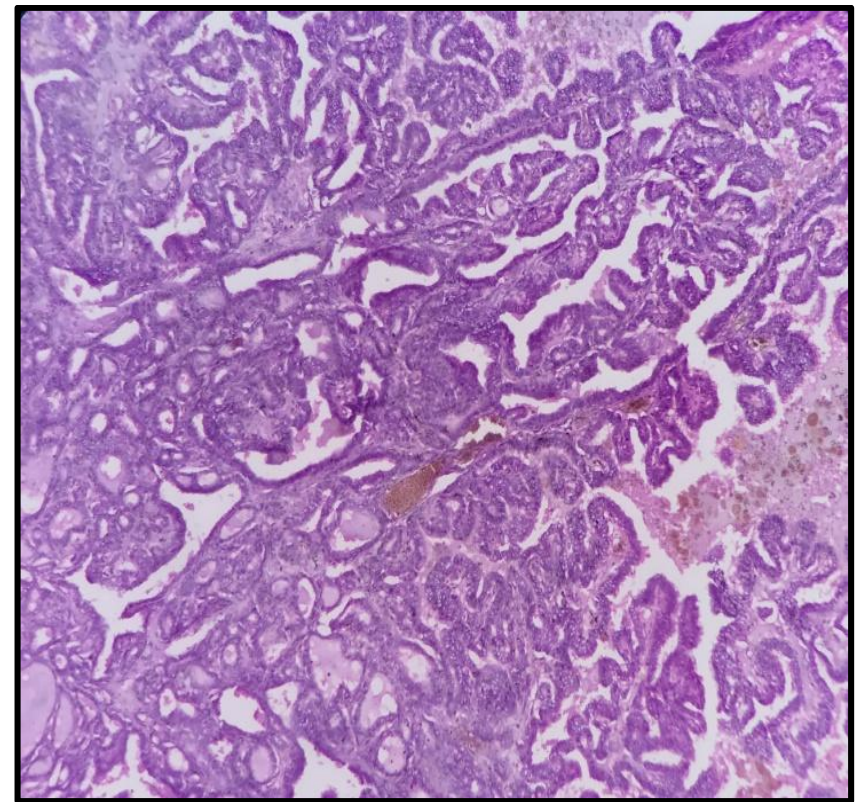

Figure 7: Histopathology of Papillary Thyroid Carcinoma showing thyroid follicular cells arranged in papillary architecture, $\mathrm{H} \& \mathrm{E}, 10 \mathrm{X}$
Table 3: Accuracy of Imprint cytology in diagnosis of thyroid lesions (Histopathological examination taken as gold standard)

\begin{tabular}{|c|c|c|c|c|c|}
\hline $\begin{array}{c}\text { Total } \\
\text { No of } \\
\text { Cases }\end{array}$ & Sensitivity & $\begin{array}{c}\text { Specificit } \\
\mathrm{y}\end{array}$ & PPV & NPV & $\begin{array}{c}\text { Acc- } \\
\text { uracy }\end{array}$ \\
\hline 53 & $87.5 \%$ & $100 \%$ & $100 \%$ & $97.8 \%$ & $98.1 \%$ \\
\hline
\end{tabular}

(PPV- Positive Predictive value)

(NPV- Negative Predictive value)

\section{Discussion}

Thyroid swellings are common clinical problem. Intraoperative cytodiagnosis of thyroid lesions could be done by Imprint Cytology. In the present study, imprint smears from fresh thyroidectomy specimens were collected intra-operatively for interpretation. Since histopathology is considered gold standard for diagnosis, the imprint smears of thyroid lesions were compared with it.

In the present study, the age of the patients ranged from 14 to 70 years, with a mean age of 39.24 years. It was comparable with the studies done by Sukumar et $\mathrm{al}^{[4]}$, Francis et $\mathrm{al}^{[5]}$ and Chehrei et $\mathrm{al}^{[2]}$. Male to female ratio was 1: 7.8. It was comparable with the studies done by Sukumar et al ${ }^{[4]}$, Taneri et $\mathrm{al}^{[3]}$ and Chehrei et $\mathrm{al}^{[2]}$. The percentage of benign and malignant lesions was comparable with the study done by Taneri et al ${ }^{[3]}$. Colloid Goitre was the commonest thyroid lesion encountered in our study based on imprint cytology. Similarly, study done by Francis et al ${ }^{[5]}$ and Anila et al ${ }^{[1]}$ showed that colloid goitre was the most common thyroid lesion. Second common lesion in the present study was Papillary Thyroid Carcinoma (13.21\%) similar to the study done by Francis et $\mathrm{al}^{[5]}(31.1 \%)$. Whereas, second most common lesion based on the study done by Anila et al ${ }^{[1]}$ was Follicular Neoplasm(23.8\%). The percentage of benign lesions in our study was found to be little higher than the study done by Sukumar et $\mathrm{al}^{[4]}$, Chehrei et $\mathrm{al}^{[2]}$ and Shashidhar et $\mathrm{al}^{[8]}$ and was little lower than the study done by Taneri et $\mathrm{al}^{[3]}$ and Anila et $\mathrm{al}^{[1]}$.

The percentage of malignant lesions in our study was found to be little higher than the study done by Taneri et $\mathrm{al}^{[3]}$ and Anila et $\mathrm{al}^{[1]}$ and was little lower than the study done by Sukumar et al ${ }^{[4]}$, Chehrei et $\mathrm{al}^{[2]}$ and Shashidhar et al ${ }^{[8]}$. 
The difference in distribution of thyroid lesions in the above studies may be due to differences in the study pattern, sample size and age group of cases studied.

According to the study done by Francis et $\mathrm{al}^{[5]}$, out of 18 cases of colloid goiter diagnosed by imprint cytology, 10 cases $(56.6 \%)$ were diagnosed as colloid goiter and 8 cases(44.4\%) were diagnosed as follicular adenoma by histopathology. Whereas, all cases of colloid goiter diagnosed in imprint cytology were confirmed to be the same by histopathology according to the study done by Anila et $\mathrm{al}^{[1]}$. In present study, out of the 31 cases of colloid goiter diagnosed in imprint cytology, 26 cases $(83.9 \%)$ were confirmed to be the same in histopathology.3 cases $(9.7 \%)$ were diagnosed as colloid goiter with cystic change, 1 case $(3.2 \%)$ as Hyperplastic nodule and 1 case $(3.2 \%)$ as Follicular adenoma in histopathology. Imprint smears of benign lesions were found to be hypocellular, which could be attributed to the misinterpretation of 5 cases $(16.1 \%)$ as colloid goiter in the present study. Imprint cytology was accurate in diagnosis of all cases of Colloid goiter with cystic change (3 cases) and Hyperplastic nodule (3 cases) in present study. One case of Hyperplastic nodule diagnosed in imprint cytology turned out to be Papillary Thyroid Carcinoma in histopathology in the study done by Francis et al. This was attributed to be due toinadequate sampling which resulted in absence of cell material representative of occult malignancy. ${ }^{[5]}$

Out of the 4 cases of Lymphocytic thyroiditis, 2 cases $(50 \%)$ were confirmed to be the same in histopathology in the present study. 2 cases $(50 \%)$ turned out to be Hashimoto thyroiditis in histopathology. This was due to the absence of askanazy cell change in the thyroid follicular cells in the smears studied.

Follicular Neoplasms are cases where Imprint cytology is problematic. As diagnosis of Follicular Carcinoma would require demonstration of capsular/vascular invasion, all cases showing cellular smears with predominant microfollicular pattern were diagnosed as Follicular Neoplasm in Imprint cytology. Further, it was reclassified as
Follicular Adenoma and Follicular Carcinoma based on the histopathological diagnosis. In the study done by Anila et $\mathrm{al}^{[1]}$, out of the 20 cases of Follicular neoplasm, 18 cases(90\%) were diagnosed as Follicular adenoma. 2 cases(10\%) turned out to be Follicular carcinoma in histopathology. In the present study, out of the 5 cases of Follicular neoplasm, 4 cases $(80 \%)$ were diagnosed as Follicular adenoma. 1 case $(10 \%)$ turned out to be Follicular carcinoma in histopathology. According to the study done by Francis et al, out of the 6 cases of Follicular neoplasm, 5 cases $(83.3 \%)$ were diagnosed as Follicular adenoma. 1 case (16.7\%) was diagnosed as Papillary Thyroid Carcinoma in histopathology. This was due to the misinterpretation of Follicular Variant of Papillary Thyroid Carcinoma as Follicular Neoplasm. ${ }^{[5]}$

Papillary Thyroid Carcinoma was diagnosed with an accuracy of $100 \%$ in all the three studies. Imprint smears from all the cases of Papillary Thyroid Carcinoma were cellular with characteristic nuclear features like nuclear grooves and intranuclear cytoplasmic inclusions which enabled the accurate diagnosis.

The sensitivity in the present study was $87.5 \%$ which is comparable with the study by Taneri et al ${ }^{[3]}$. In the current study the specificity was $100 \%$ which is the same as observed by Anila et $\mathrm{al}^{[1]}$ and Shashidhar et $\mathrm{al}^{[8]}$ and was higher than the study done by Sukumar et $\mathrm{al}^{[4]}$, Taneri et $\mathrm{al}^{[3]}$ and Chehrei et $\mathrm{al}^{[2]}$.

Positive Predictive Value (PPV) was $100 \%$ similar to study done by Anila et al ${ }^{[1]}$ and Shashidhar et al ${ }^{[8]}$. Negative Predictive Value (NPV) was $97.8 \%$ which is comparable with study by Taneri et al ${ }^{[3]}$ and Anila et $\mathrm{al}^{[1]}$.

The diagnostic accuracy in the present study was $98.1 \%$. The value was almost similar to that found in the study done by Anila et al ${ }^{[1]}$.

In our study, none of benign lesion was diagnosed as malignant. Hence, there were no false positive cases in our study. Considering the high diagnostic accuracy and high specificity of imprint cytology, it can be used as a good tool for diagnosing thyroid lesions. 


\section{Conclusion}

Imprint cytology is a simple, cost effective and rapid intraoperative diagnostic technique.

Due to high accuracy rate achieved by this technique, this can be an useful guide in making intraoperative therapeutic decision quickly. Touch imprint cytology has further advantage of being inexpensive, offers excellent cellular details and no expensive instruments are needed.

Thus in the light of the study we suggest that imprint cytology can provide a useful method for safe, dependable, rapid and accurate management of thyroid lesions.

\section{Acknowledgement}

We thank all teaching staff, Department of Pathology, MMC \& RI for their valuable support for the study.

\section{References}

1. Anila K R , Krishna G. Role of imprint cytology in intraoperative diagnosis of thyroid lesions. Gulf J Oncolog 2014;1:73-8

2. Chehrei A, Ahmadinejad M, Tabatabaee S A, Hashemi S M, Kianinia M, Fatesh S, et al. Touch imprint and crash preparation and intraoperative cytology versus frozen section in thyroid nodules. J Res Med Sci 2012; $17 ; 475-80$

3. Taneri F, Poyraz A, Salman B, Tekin E, Akuerek N, Bayram O, et al. Using imprint cytology and frozen section in determining the surgical strategies for thyroid pathologies. Endocrine Regulations, June 2001; Vol 35; 71-74

4. Sukumar Shaha, A J E Nahar Rahman. Comparative study of imprint cytology and frozen section in the intraoperative diagnosis of thyroid lesions. Bangladesh $\mathbf{J}$ of Pathol:2009;24(1):12-15.

5. Francis I M, Das D K. Role of FNA, intraoperative cytology and frozen section in the diagnosis of breast lumps and thyroid lesions. Int J Kuwait University Health Sciences Centre. 1999;8:173-82.
6. Belleannée G, Verdebout J, Feoli F et al . Role of cytology and frozen sections in the intraoperative examination of the thyroid: Comparison of two experiences. Clin Exp Pathol. 1999;47:273-77.

7. Manafis K. An intraoperative consultation. Usefulness, reason and accuracy of the method. Arch Hell Pathol .1997;11:472-7.

8. Shashidar H B, Vani D, Ashwini N S, Sandhya M. Cyto-histological correlative study of thyroid neoplasms by imprint method. Int J Sci Stud 2015:3(6):140-144.

9. Faquin WC. The thyroid gland: recurring problems in histologic and cytologic evaluation. Arch Pathol Lab Med. 2008 Apr;132(4):622-32.

10. Khalid A, Anwar U I H .Touch imrint cytology versus frozen section as Intraoperative consultation diagnosis. Intern J Pathol.2004;2(2):63-70.

11. S Veneti, Toufexi H, Xenitides $\mathrm{J}$ et al. Imprint cytology. Acta Cytologica.1996; 40:649-52.

12. Ranjan A, Chandoke RK, Chauhan $\mathrm{N}$ et al. Oncology, study of tumors by imprint cytology. Indian J Clin Pract. 2013;24:47277. 